\title{
Optimum nitrogen fertilization of Calophyllum inophyllum seedlings under greenhouse conditions
}

\author{
Wentao ZOU ${ }^{1}$, Ruifeng JIA ${ }^{2}$, Jinchang YANG $(\bowtie)^{1}$, Rongsheng LI $^{1}$, Guangtian YIN ${ }^{1}$ \\ 1 Research Institute of Tropical Forestry, Chinese Academy of Forestry, Guangzhou 510520, China \\ 2 Rural Work Bureau of High Tech Industry Development Zone in Huizhou, Huizhou 516005, China
}

\begin{abstract}
A greenhouse pot experiment was conducted to study the effects of nitrogen fertilization on Calophyllum inophyllum seedlings grown with $0,50,100,150$, 200, 300, 400 and $600 \mathrm{mg} \mathrm{N}$ per seedling according to exponential functions. Seedling height, root collar diameter, leaf area and total biomass increased with increasing fertilization from 0 to $200 \mathrm{mg} \mathrm{N}$ per seedling and decreased with further increase in fertilization from 300 to $600 \mathrm{mg} \mathrm{N}$ per seedling. The net photosynthetic rate, stomatal conductance, intercellular $\mathrm{CO}_{2}$ concentration and transpiration rate of $C$. inophyllum seedlings showed a unimodal parabolic trend, with peak values of $7.29 \mu \mathrm{mol} \cdot \mathrm{m}^{-2} \cdot \mathrm{s}^{-1}, 0.071 \mathrm{~mol} \cdot \mathrm{m}^{-2} \cdot \mathrm{s}^{-1}, 220 \mu \mathrm{mol} \cdot \mathrm{mol}^{-1}$ and $1.34 \mathrm{mmol} \cdot \mathrm{m}^{-2} \cdot \mathrm{s}^{-1}$, respectively, when the rate of fertilization was $200 \mathrm{mg} \mathrm{N}$ per seedling. Photosynthetic gas exchange parameters were significantly different among nitrogen treatments. Based on the critical values of leaf $\mathrm{N}$ and $\mathrm{P}$ concentration and $\mathrm{N} / \mathrm{P}$ ratio, the optimum amount of nitrogen of $C$. inophyllum seedlings was 200 $400 \mathrm{mg}$ per seedling for leaf $\mathrm{N}$ and $\mathrm{P}$ concentration, and $100-400 \mathrm{mg}$ per seedling for N/P ratio. It was concluded that $200-400 \mathrm{mg} \mathrm{N}$ per seedling was the most suitable nitrogen range for $C$. inophyllum seedlings.
\end{abstract}

Keywords Calophyllum inophyllum, growth, nitrogen fertilization, nutrient status, photosynthesis

\section{Introduction}

Nitrogen is a key factor affecting seedling growth and development ${ }^{[1-3]}$, and is important in regulating plant

Received August 29, 2016; accepted December 1, 2016

Correspondence: fjyjc@126.com growth and metabolism. Suitable nitrogen fertilization can lead to high-quality seedling production ${ }^{[4,5]}$. Therefore, the amount and effectiveness of nitrogen fertilizer has been a strong research focus. Currently in seedling production, nitrogen use efficiency is low because of inappropriate fertilization methods. Studies have shown that 32\%-85\% of nitrogen fertilizer cannot be absorbed or used by forest seedlings in the nurseries ${ }^{[6]}$.

During the seedling growth, fertilization methods have usually involved supplying fertilizers in equal doses. This method results in a surplus of nutrients at the beginning followed by deficiency later in seedling growth ${ }^{[7]}$. Since the 1980s, researchers have discovered that exponential fertilization can actively enhances nutrient utilization efficiency ${ }^{[8]}$, including black spruce (Picea mariana $)^{[9-11]}$, white spruce (Picea glauca) ${ }^{[12]}$, Norway spruce (Picea abies $)^{[13]}$ and birch (Betula alnoides $)^{[14]}$.

Calophyllum inophyllum is a salt-tolerant and windresistant evergreen species distributed in the tropical and subtropical regions of Asia, Oceania and South America ${ }^{[15]}$. In China, it is mainly found in Hainan Island ${ }^{[16]}$. C. inophyllum has a high value for development and utilization because of its ecological, medicinal and seed oil functions. Researchers have extensively investigated the biological characteristics ${ }^{[17]}$, ecological functions ${ }^{[18,19]}$, medicinal efficacy ${ }^{[20,21]}$ and economic values $^{[22,23]}$ of $C$. inophyllum. However, little is known about its nutrient requirements, which potentially creates inefficiencies in its silviculture.

The objective of this study was to determine the optimum nitrogen fertilization for $C$. inophyllum seedlings grown under greenhouse conditions. Responses of seedlings to nitrogen fertilizer treatments, including growth characteristics, photosynthetic gas exchange parameters and nutrient status, were examined. Optimum fertilization was determined by the critical value method to provide a theoretical basis for fertilization practice and cultivation technology for this species. 


\section{Materials and methods}

\subsection{Plant materials and growth condition}

Healthy one-month old seedlings of $C$. inophyllum about $6.5 \mathrm{~cm}$ in height were grown in a greenhouse at the Research Institute of Tropical Forestry, Guangzhou, China. The seedlings were cultured in $12 \mathrm{~cm} \times 15 \mathrm{~cm}$ round, tapered plastic pots filled with peat, vermiculite and pearlite $(3: 2: 2 \mathrm{v} / \mathrm{v})$. Each pot was irrigated to $75 \%-80 \%$ of field capacity determined gravimetrically at transplanting ${ }^{[24]}$. Plant Prod (Plant Products Co. Ltd, Brampton, Ontario, Canada) soluble fertilizer $\left(\mathrm{N}_{2}: \mathrm{P}_{2} \mathrm{O}_{5}: \mathrm{K}_{2} \mathrm{O}\right.$, 20:10:20) was applied twice per week. Plastic bags were placed inside the pots to prevent drainage of water and nutrients. The average daily temperature in the greenhouse ranged from 23 to $38^{\circ} \mathrm{C}$ and night temperature from 14 to $22^{\circ} \mathrm{C}$. Relative humidity ranged from $34 \%$ to $78 \%$. To reduce the edge effects, the positions of the posts were rotated every two weeks. Fungal diseases were prevented by injecting a $0.2 \%$ solution of carbendazim into the growth medium.

\subsection{Experimental design and fertilizer treatments}

The fertilizer was dissolved in distilled water and the same volume carefully applied to seedlings using a syringe. To ensure similar moisture conditions of the seedlings, each seedling pot was weighed and an appropriate amount of water added.

Eight nutrient treatments (N1 to $\mathrm{N} 8=0,50,100,150$, 200, 300, 400 and $600 \mathrm{mg} \mathrm{N}$ per seedling) were applied to seedlings with an exponentially increasing amount applied from June to December 2010 (Table 1). Each treatment had four replicates; each replicate consisted of 12 seedlings, totalling 384 seedlings across all treatments. Fertilizer treatments commenced two weeks after transplanting and were continued for 24 weeks.

The fertilizer treatments followed exponential functions to match nutrient supply with seedling growth according to Salifu and Timmer ${ }^{[11]}$.

$$
N_{t}=N_{s}\left(e^{r t-1}\right)-N_{(t-1)}
$$

where $N_{t}$ is the amount of $\mathrm{N}$ to be added at time $t$ for a given relative additional rate $r, N_{s}$ is the initial quantity of $\mathrm{N}$ at the commencement of the treatment, and $N_{(t-1)}$ is the cumulative amount of $\mathrm{N}$ added. $r$ was calculated using the method described by Dumroese et al. ${ }^{[25]}$.

$$
N_{T}=N_{s}\left(e^{r t-1}\right)
$$

where $N_{T}$ is the desired amount to be added over the number of fertilizer applications $(t=12) . N_{s}$ was predetermined from an additional 60 seedlings at $12.1 \mathrm{mg} \mathrm{N}$ per seedling.

\subsection{Measurements}

Root collar diameter and height of all seedlings were measured at the end of the experiment. Total leaf area of four seedlings randomly selected from each treatment was determined using a hand-held laser leaf area meter (CI203, CID Bio-Science, Inc., Camas, WA, USA), and net photosynthesis, transpiration rate, stomatal conductance and intercellular $\mathrm{CO}_{2}$ concentration were also measured using a portable photosynthesis measurement system (Licor-6400, Li-cor Biosciences, Lincoln, NE, USA). Four seedlings of each treatment were harvested and separated into leaves, stems and roots, and then oven-dried at $65^{\circ} \mathrm{C}$ for $48 \mathrm{~h}$ to estimate biomass production. The dried

\begin{tabular}{|c|c|c|c|c|c|c|c|c|}
\hline \multirow{2}{*}{ Week } & \multicolumn{8}{|c|}{ Nitrogen fertilizer per seedling/mg } \\
\hline & N1 & $\mathrm{N} 2$ & N3 & N4 & N5 & N6 & N7 & N8 \\
\hline 0 & 0 & 2.6 & 4.0 & 4.9 & 5.7 & 6.8 & 7.6 & 8.9 \\
\hline 2 & 0 & 2.8 & 4.6 & 5.7 & 6.7 & 8.2 & 9.5 & 11.3 \\
\hline 4 & 0 & 3.0 & 5.0 & 6.6 & 7.9 & 10.0 & 11.8 & 14.6 \\
\hline 6 & 0 & 3.6 & 5.7 & 7.6 & 9.3 & 12.2 & 14.7 & 18.8 \\
\hline 8 & 0 & 3.6 & 6.4 & 8.8 & 11.0 & 14.9 & 18.3 & 24.2 \\
\hline 10 & 0 & 3.9 & 7.2 & 10.3 & 13.0 & 18.1 & 22.8 & 31.1 \\
\hline 12 & 0 & 4.2 & 8.1 & 11.9 & 15.4 & 22.1 & 28.4 & 39.9 \\
\hline 14 & 0 & 4.5 & 9.2 & 13.8 & 18.2 & 26.9 & 35.3 & 51.3 \\
\hline 16 & 0 & 4.9 & 10.3 & 15.9 & 21.6 & 32.8 & 44.0 & 66.0 \\
\hline 18 & 0 & 5.3 & 11.6 & 18.4 & 25.5 & 39.9 & 54.7 & 84.8 \\
\hline 20 & 0 & 5.8 & 13.1 & 21.4 & 30.1 & 48.7 & 68.2 & 109.0 \\
\hline 22 & 0 & 6.2 & 14.8 & 24.7 & 35.6 & 59.3 & 84.9 & 140.1 \\
\hline Total & 0 & 50.0 & 100.0 & 150.0 & 200.0 & 300.0 & 400.0 & 600.0 \\
\hline
\end{tabular}

Table 1 Program for exponential nitrogen fertilization of Calophyllum inophyllum seedlings 
seedling samples were finely milled using a $\mathrm{H}_{2} \mathrm{SO}_{4}$ and $\mathrm{K}_{2} \mathrm{SO}_{4}-\mathrm{CuSO}_{4}$ mixture catalyst to determine total $\mathrm{N}$ by the diffusion method, and were wet-digested using $\mathrm{HNO}_{3}$ $\mathrm{HClO}_{4}$ mixture solution to analyze $\mathrm{P}$ by the molybdenum blue method and $\mathrm{K}$ by atomic absorption.

\subsection{Data analysis}

After checking for normality and homoscedasticity, the effects of nutrient application on seedling height, root collar diameter, leaf area and biomass were assessed using a one-way analysis of variance by SPSS 16.0 (IBM, Armonk, NY, USA). Significant differences among treatment means were further assessed using Duncan's multiple range tests at the 5\% level. Effects of nitrogen fertilization on photosynthetic gas exchange parameters and leaf nutrient status were plotted using Excel 2003 (Microsoft Corp. Redmond, WA, USA). Regression equations between nutrient concentration or ratio and total biomass of the seedlings were fitted and then diagnostic equations were accepted that were statistically significant. The critical value and the optimum concentration range were calculated using the nutrient concentration which corresponded to $90 \%$ maximum biomass from the equa$\operatorname{tion}^{[26,27]}$.

\section{Results}

\subsection{Root collar diameter, height and leaf area}

The root collar diameter, height and leaf area at the end of experiment of $C$. inophyllum seedlings are shown in Table 2. The values recorded for these growth parameters increased with an increase in nitrogen fertilizer peaking at N4 to N5 (150-200 mg N per seedling) and then decreased with further increase in the nitrogen fertilizer levels.

\subsection{Biomass}

Total biomass of $C$. inophyllum seedlings increased with increasing nitrogen fertilizer from $\mathrm{N} 1$ to $\mathrm{N} 5$, and decreased with further increase in the nitrogen fertilization from N6 to N8 (Fig. 1). The greatest biomass production was observed in N5 with $10.4 \mathrm{~g}$ per seedling compared to the 5.5 g per seedling in N1.

\subsection{Photosynthetic gas exchange parameters}

The net photosynthetic rate, stomatal conductance, intercellular $\mathrm{CO}_{2}$ concentration and transpiration rate of C. inophyllum seedlings showed a unimodal parabolic trend. The peak values recorded for $200 \mathrm{mg} \mathrm{N}$ per seedling were $7.29 \mu \mathrm{mol} \cdot \mathrm{m}^{-2} \cdot \mathrm{s}^{-1}, 0.071 \mu \mathrm{mol} \cdot \mathrm{m}^{-2} \cdot \mathrm{s}^{-1}$, $220 \mu \mathrm{mol} \cdot \mathrm{mol}^{-1}$ and $1.34 \mathrm{mmol} \cdot \mathrm{m}^{-2} \cdot \mathrm{s}^{-1}$ (Fig. 2).

\subsection{Leaf nutrient status}

As the amount of nitrogen supplied increased, leaf nitrogen concentration increased from $6.28 \mathrm{mg} \cdot \mathrm{g}^{-1}$ in N1 to $19.4 \mathrm{mg} \cdot \mathrm{g}^{-1}$ in $\mathrm{N} 8$ (Table 3). Leaf nitrogen content increased with increasing nitrogen fertilization from $\mathrm{N} 1$ to $\mathrm{N} 5$, followed by a slight decline in N6, then increased again from N7 to N8. In contrast, leaf biomass of the seedlings increased with increasing nitrogen fertilizer from $\mathrm{N} 1$ to $\mathrm{N} 5$ then declined from $\mathrm{N} 6$ to $\mathrm{N} 8$.

\subsection{The optimal nitrogen determined by the critical value}

There were parabolic relationships between biomass and leaf $\mathrm{N}$ and $\mathrm{P}$ concentration, and $\mathrm{N} / \mathrm{P}$ ratio as illustrated by the scatter plots (Fig. 3).

There were significant differences $(P<0.01)$ between leaf $\mathrm{N}$ and $\mathrm{P}$ concentrations, and $\mathrm{N} / \mathrm{P}$ ratio (Table 4$)$. The parabolic relationships between leaf $K$ concentration, $N / K$ and $\mathrm{P} / \mathrm{K}$ ratio and seedling biomass were not significantly different.

The critical values of the leaf $\mathrm{N}$ and $\mathrm{P}$ concentrations, and N/P ratio of $C$. inophyllum seedlings were $9.49 \mathrm{mg} \cdot \mathrm{g}^{-1}, 0.48 \mathrm{mg} \cdot \mathrm{g}^{-1}$ and 17.2 , respectively, and their optimum concentration ranges were $9.49-17.04 \mathrm{mg} \cdot \mathrm{g}^{-1}$, $0.48-0.73 \mathrm{mg} \cdot \mathrm{g}^{-1}$ and $17.2-23.7$, respectively. There-

Table 2 Effects of nitrogen fertilizer treatments on growth of Calophyllum inophyllum seedlings

\begin{tabular}{|c|c|c|c|c|}
\hline Nitrogen treatment & Nitrogen fertilizer per seedling/mg & Seedling height $/ \mathrm{cm}$ & Root collar diameter $/ \mathrm{cm}$ & Leaf area $/ \mathrm{cm}^{2}$ \\
\hline$\overline{\mathrm{N} 1}$ & 0 & $13.9 \pm 0.80^{\mathrm{d}}$ & $0.52 \pm 0.01^{\mathrm{f}}$ & $127 \pm 11.3^{\mathrm{g}}$ \\
\hline $\mathrm{N} 2$ & 50 & $17.2 \pm 2.15^{\mathrm{c}}$ & $0.55 \pm 0.03^{\mathrm{de}}$ & $193 \pm 19.0^{\mathrm{f}}$ \\
\hline N3 & 100 & $18.7 \pm 0.84^{\mathrm{bc}}$ & $0.56 \pm 0.06^{\text {cde }}$ & $242 \pm 17.8^{\mathrm{de}}$ \\
\hline $\mathrm{N} 4$ & 150 & $21.8 \pm 2.14^{\mathrm{a}}$ & $0.63 \pm 0.01^{\mathrm{ab}}$ & $312 \pm 15.1^{\mathrm{ab}}$ \\
\hline N5 & 200 & $22.1 \pm 1.51^{\mathrm{a}}$ & $0.65 \pm 0.01^{\mathrm{a}}$ & $327 \pm 15.0^{\mathrm{a}}$ \\
\hline N6 & 300 & $21.0 \pm 0.22^{\mathrm{ab}}$ & $0.61 \pm 0.01^{\mathrm{abc}}$ & $289 \pm 6.4^{\mathrm{bc}}$ \\
\hline N7 & 400 & $20.4 \pm 0.47^{\mathrm{ab}}$ & $0.60 \pm 0.02^{\mathrm{bcd}}$ & $266 \pm 13.0^{\mathrm{cd}}$ \\
\hline N8 & 600 & $19.6 \pm 2.28^{\mathrm{abc}}$ & $0.59 \pm 0.01^{\mathrm{bcd}}$ & $234 \pm 21.8^{\mathrm{e}}$ \\
\hline
\end{tabular}

Note: Each value is the mean of four replicates \pm SE. For each column, different letters denote significant differences among the treatments according to Duncan's Multiple Range Test $(P<0.05)$ 


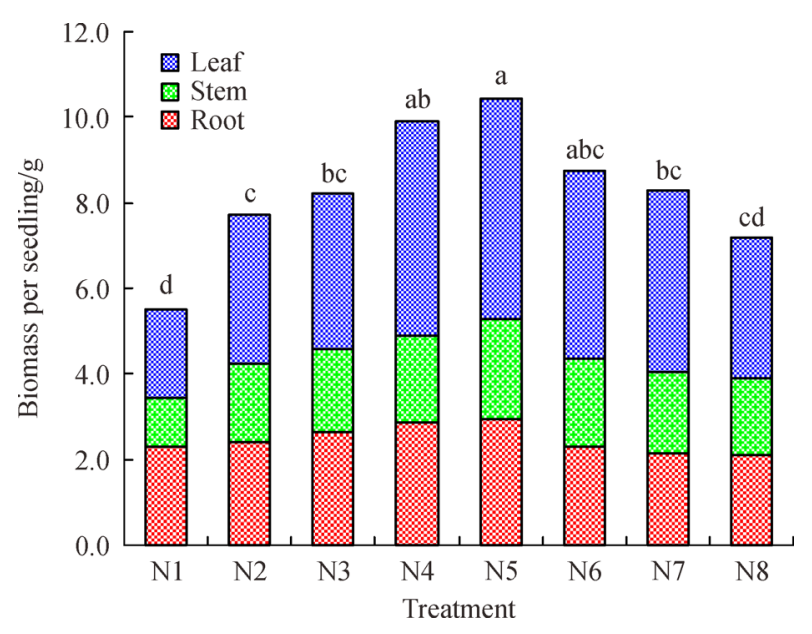

Fig. 1 Effects of nitrogen fertilizer treatments on biomass of Calophyllum inophyllum seedlings. Different letters above the columns indicate significant differences between treatments according to Duncan's Multiple Range Test $(P<0.05)$. Data are means $\pm \operatorname{SE}(n=4)$.

fore, given these optimum concentration ranges, the optimum amount of nitrogen for seedlings for these three measures were 200-400 mg per seedling, 200-400 mg per seedling and 100-400 mg per seedling, respectively.
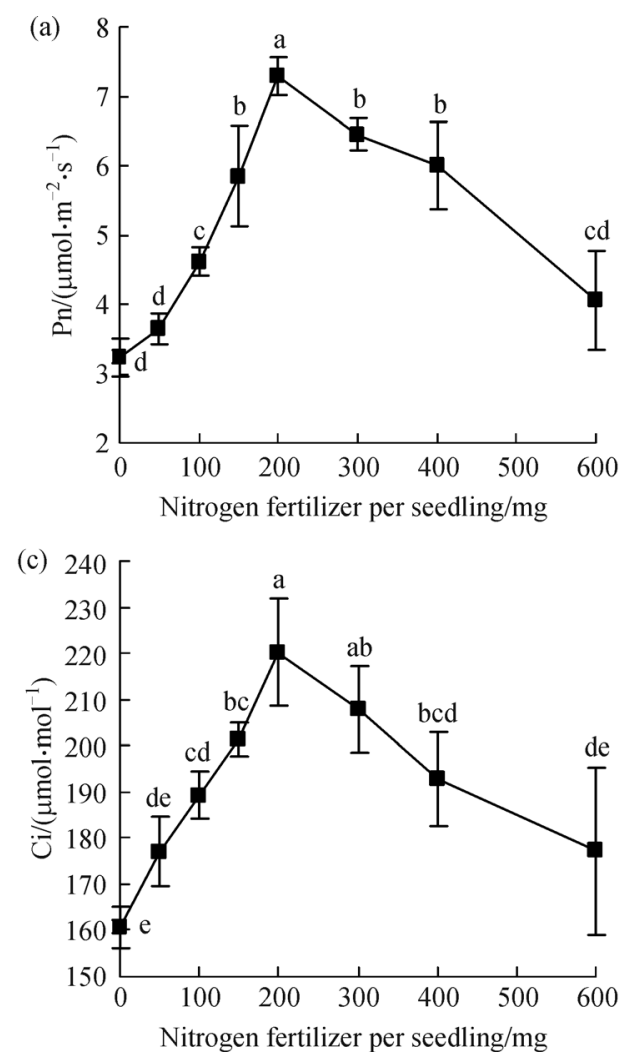

\section{Discussion}

Numerous research results have shown that nitrogen influences the growth of young trees ${ }^{[3,5,28]}$. In our study, we observed that seedling height, root collar diameter, leaf area and biomass of $C$. inophyllum seedlings were enhanced by nitrogen fertilization. Dosage of $200 \mathrm{mg} \mathrm{N}$ per seedling appears to be the critical point for optimum growth of the seedlings. When the application was more than $200 \mathrm{mg} \mathrm{N}$ per seedling, excessive nitrogen reduced carbon assimilation and RuBP carboxylase activity, resulting in decreased photosynthesis and increased seedling respiration. In addition, photosynthesis was weakened while respiration of seedlings was strengthened. The growth of young leaves and seedlings was slow, thus the appropriate amount of nitrogen fertilizer can promote seedling growth and development. Our results are in accord with those reported by other researchers ${ }^{[29-31]}$.

The peak values of net photosynethetic rate, stomatal conductance, intercellular $\mathrm{CO}_{2}$ concentration and transpiration rate of $C$. inophyllum seedlings were obtained with fertilization of $200 \mathrm{mg} \mathrm{N}$ per seedling (N5). Nitrogen fertilizer treatments had significant effects on the photosynthetic gas exchange parameters (Fig. 2), which suggests that an appropriate amount of nitrogen can enhance the
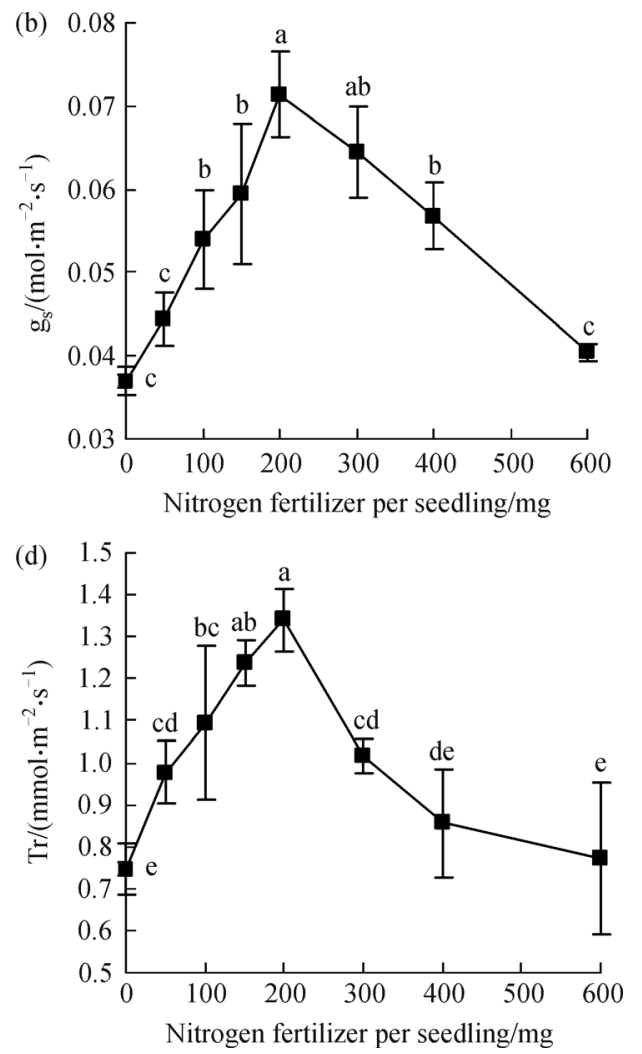

Fig. 2 Effects of nitrogen fertilizer treatments on photosynthetic gas exchange parameters of Calophyllum inophyllum seedlings. (a) Net photosynthetic rate; (b) stomatal conductance; (c) intercellular $\mathrm{CO}_{2}$ concentration; (d) transpiration rate. Different letters indicate significant differences between treatments according to Duncan's Multiple Range Test $(P<0.05)$. Data are means $\pm \operatorname{SE}(n=4)$. 

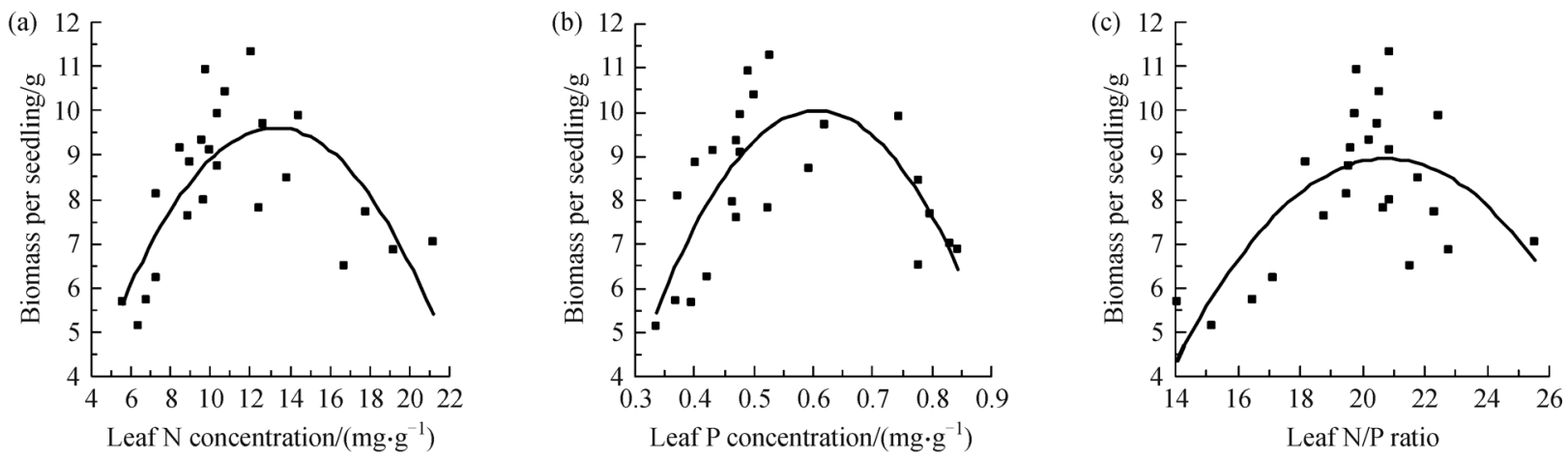

Fig. 3 The quadratic relationship between leaf $\mathrm{N}$ and $\mathrm{P}$ concentrations, N/P ratio and biomass of Calophyllum inophyllum seedlings. (a) The relationship between leaf $\mathrm{N}$ and biomass; (b) the relationship between leaf $\mathrm{P}$ and biomass; (c) the relationship between leaf $\mathrm{N} / \mathrm{P}$ ration and biomass.

Table 3 Effects of nitrogen fertilizer treatments on leaf nutrient situation of Calophyllum inophyllum seedlings

\begin{tabular}{lcccc}
\hline Nitrogen treatment & Nitrogen fertilizer per seedling/mg & Leaf N concentration/ $\left(\mathrm{mg} \cdot \mathrm{g}^{-1}\right)$ & Leaf biomass per seedling/g & Leaf N content per seedling/mg \\
\hline N1 & 0 & $6.3 \pm 0.37^{\mathrm{f}}$ & $2.06 \pm 0.08^{\mathrm{c}}$ & $12.9 \pm 0.95^{\mathrm{d}}$ \\
N2 & 50 & $7.8 \pm 0.57^{\mathrm{ef}}$ & $3.48 \pm 0.22^{\mathrm{b}}$ & $27.3 \pm 3.16^{\mathrm{c}}$ \\
N3 & 100 & $9.0 \pm 0.36^{\mathrm{e}}$ & $3.66 \pm 0.46^{\mathrm{b}}$ & $32.8 \pm 3.44^{\mathrm{c}}$ \\
N4 & 150 & $9.8 \pm 0.12^{\mathrm{de}}$ & $5.02 \pm 0.26^{\mathrm{a}}$ & $49.0 \pm 2.73^{\mathrm{b}}$ \\
N5 & 200 & $11.1 \pm 0.51^{\mathrm{cd}}$ & $5.16 \pm 0.29^{\mathrm{a}}$ & $57.4 \pm 5.90^{\mathrm{ab}}$ \\
N6 & 300 & $11.8 \pm 0.72^{\mathrm{c}}$ & $4.38 \pm 0.22^{\mathrm{ab}}$ & $51.7 \pm 3.35^{\mathrm{ab}}$ \\
N7 & 400 & $15.0 \pm 0.89^{\mathrm{b}}$ & $4.23 \pm 0.58^{\mathrm{ab}}$ & $62.9 \pm 6.47^{\mathrm{a}}$ \\
N8 & 600 & $19.4 \pm 0.97^{\mathrm{a}}$ & $3.30 \pm 0.32^{\mathrm{b}}$ & $63.5 \pm 3.02^{\mathrm{a}}$ \\
\hline
\end{tabular}

Note: Each value is the mean of four replicates \pm SE. For each column, different letters denote significant differences between the treatments according to Duncan's Multiple Range Test $(P<0.05)$.

Table 4 Regression equations for nutrient concentration or ratio versus biomass of Calophyllum inophyllum seedlings

\begin{tabular}{lcccc}
\hline Dependent variable & Independent variable & Regressive equation & $R$ value & Significant \\
\hline \multirow{4}{*}{$X 1(\mathrm{~N})$} & $Y=-0.0675 X 1^{2}+1.791 X 1-2.248$ & 0.735 & $P<0.01$ \\
& $X 2(\mathrm{P})$ & $Y=-63.02 X 2^{2}+76.33 X 2-13.08$ & 0.732 & $P<0.01$ \\
$(Y)$ & $X 3(\mathrm{~K})$ & $Y=-0.0505 X 3^{2}+1.274 X 3+0.8612$ & 0.346 & 0.687 \\
Biomass & $X 4(\mathrm{~N} / \mathrm{P})$ & $Y=-0.1009 X 4^{2}+4.191 X 4-34.59$ & 0.623 & $P<0.01$ \\
& $X 5(\mathrm{~N} / \mathrm{K})$ & $Y=-1.319 X 5^{2}+9.141 X 5+0.4887$ & 0.549 & $P>0.05$ \\
& $X 6(\mathrm{P} / \mathrm{K})$ & $Y=2139 X 6^{2}-51.49 X 6+5.565$ & & \\
\end{tabular}

photosynthetic capacity of $C$. inophyllum seedlings. Brown et al. concluded that the photosynthetic rates increased linearly with nitrogen addition to a maximum at $21 \mathrm{mg} \cdot \mathrm{g}^{-1}$ and declined at higher rates of nitrogen addition when the seedlings of the evergreen conifers Picea sitchensis, Thuja plicata and Tsuga heterophylla were fertillized with nitrogen using exponentially increasing rates ${ }^{[32]}$. Nakaji et al. found the net photosynthetic rate of Pinus densiflora was reduced by the high nitrogen treatments in the first half of the growing season, and suggested that the reduced photosynthesis under high nitrogen dosage was mainly due to the decline of both $\mathrm{CO}_{2}$ fixation and photosystem II activity in the chloroplasts ${ }^{[33]}$.

Most studies have used exponential fertilization to indicate the relationship between nitrogen concentration and supply. Almost all these studies considered that seedling biomass and nitrogen content had an increasesteady-decline trend, with nitrogen concentration rising continuously as nitrogen supply increased ${ }^{[34]}$. We came to the same conclusion from the findings presented here (Fig. 3). Salifu and Jacobs studied the exponential fertilization in $P$. mariana and observed the optimum nitrogen range was $30-64 \mathrm{mg} \mathrm{N}$ per seedling ${ }^{[35]}$. These authors also found the most appropriate amount of nitrogen 
for Quercus rubra was $25-100 \mathrm{mg} \mathrm{N}$ per seedling. Wei et al. reported that $24.3-33.7 \mathrm{mg} \mathrm{N}$ per seedling resulted in the greatest biomass and highest nitrogen efficiency in Larix olgensis ${ }^{[30]}$. Chen et al. determined that the suitable nitrogen range for $B$. alnoideswas $200-400 \mathrm{mg} \mathrm{N}$ per seedling using exponential fertilization ${ }^{[14]}$. In our research, leaf biomass reached its peak at N5 treatment $(200 \mathrm{mg} \mathrm{N}$ per seedling), with the leaf nutrient level being satisfactory for seedling growth. From N6 to N8, leaf biomass of C. inophyllum seedlings decreased while the leaf nitrogen concentration increased, indicating that leaf nutrient status was in the luxury consumption under these conditions. This luxury nutrient consumption by seedlings and the concentration effect resulting from reduction in the leaf biomass may cause a continuing increase of leaf nitrogen concentration. Therefore, we conclude that $200-400 \mathrm{mg} \mathrm{N}$ per seedling is the most appropriate nitrogen range for C. inophyllum seedlings. All results from this and other studies indicate that there are marked differences for nutrient requirements between different tree species ${ }^{[13,36]}$.

The optimum nitrogen range in our study was determined by the early growth performance of newlytransplanted seedlings. However, it should be noted that there are likely to be differences between greenhouse and field environments ${ }^{[37]}$. Further study in the field is thus warranted to provide a sound theoretical basis for fertilization of C. inophyllum.

\section{Conclusions}

Nitrogen fertilization had significant effects on the height, root collar diameter, leaf area, total biomass, net photosynthetic rate, stomatal conductance, intercellular $\mathrm{CO}_{2}$ concentration. Transpiration rate of $C$. inophyllum seedlings, and the peak values of the eight measures were obtained with fertilization of $200 \mathrm{mg} \mathrm{N}$ per seedling. It was concluded that $200-400 \mathrm{mg} \mathrm{N}$ per seedling was the most suitable nitrogen fertilization range for C. inophyllum seedlings.

Acknowledgements This research was supported by the Introduction of International Advanced Forestry Science and Technology Project (2014-473). We are grateful to Liang Kou and Jianguang Li for their assistance in the greenhouse experiment. We thank Lesu Yang and Bin Yu for nutrient determinations and Dr. Khongsak Pinyopusarerk for valuable comments on earlier draft of the manuscript.

Compliance with ethics guidelines Wentao Zou, Ruifeng Jia, Jinchang Yang, Rongsheng Li, and Guangtian Yin declare that they have no conflicts of interest or financial conflicts to disclose.

This article does not contain any studies with human or animal subjects performed by any of the authors.

\section{References}

1. Burdett A. Physiological processes in plantation establishment and the development of specifications for forest planting stock. Canadian Journal of Forest Research, 1990, 20(4): 415-427

2. Nambiar E K S, Sands R. Competition for water and nutrients in forests. Canadian Journal of Forest Research , 1993, 23(10): 19551968

3. Stumpf B, Yan F, Honermeier B. Nitrogen fertilization and maturity influence the phenolic concentration of wheat grain (Triticum aestivum). Journal of Plant Nutrition and Soil Science, 2015, 178 (1): 118-125

4. Imo M, Timmer V R. Nitrogen uptake of mesquite seedlings at conventional and exponential fertilization schedules. Soil Science Society of America Journal, 1992, 56(3): 927-934

5. Paul Jackson D, Kasten Dumroese R, Barnett J P. Nursery response of container Pinus palustris seedlings to nitrogen supply and subsequent effects on outplanting performance. Forest Ecology and Management, 2012, 265(1): 1-12

6. Juntunen M L, Hammar T, Rikala R. Leaching of nitrogen and phosphorus during production of forest seedlings in containers. Journal of Environmental Quality, 2002, 31(6): 1868-1874

7. Imo M, Timmer V R. Growth, nutrient allocation and water relations of mesquite seedlings at differing fertilization schedules. Forest Ecology and Management, 1992, 55(1-4): 279-294

8. Ingestad T, Lund A B. Theory and techniques for steady state mineral nutrition and growth of plants. Scandinavian Journal of Forest Research, 1986, 1(1-4): 439-453

9. Timmer V R, Armstrong G, Miller B. Steady-state nutrient preconditioning and early outplanting performance of containerized black spruce seedlings. Canadian Journal of Forest Research, 1991, 21(5): 585-594

10. Quoreshi A M, Timmer V R. Early outplanting performance of nutrient-loaded containerized black spruce seedlings inoculated with Laccaria bicolor: a bioassay study. Canadian Journal of Forest Research, 2000, 30(5): 744-752

11. Salifu K F, Timmer V R. Optimizing nitrogen loading of Picea mariana seedlings during nursery culture. Canadian Journal of Forest Research, 2003, 33(7): 1287-1294

12. McAlister J A, Timmer V R. Nutrient enrichment of white spruce seedlings during nursery culture and initial plantation establishment. Tree Physiology, 1998, 18(3): 195-202

13. Rytter L, Ericsson T, Rytter R. Effects of demand-driven fertilization on nutrient use, root: plant ratio and field performance of Betula pendula and Picea abies. Scandinavian Journal of Forest Research, 2003, 18(5): 401-415

14. Chen L, Zeng J, Xu D P, Zhao Z G, Guo J J, Lin K Q, Sha E. Effects of exponential nitrogen loading on growth and foliar nutrient status of Betula alnoides seedlings. Sceintia Silvae Sinicae, 2010, 46(5): 35-40

15. Dweck A C, Meadows T. Tamanu (Calophyllum inophyllum) - the African, Asian, Polynesian and Pacific Panacea. International Journal of Cosmetic Science, 2002, 24(6): 341-348

16. Wu D. Plant Directory in the coastal island in Hainan and Guangdong province. Beijing: Science Press, 1994.

17. Ji X, Zeng D, Huang S. Calophyllum inophyllum, a tree species for landscape in south subtropical zone. Chinese Journal of Tropical Agriculture, 2004, 24(6): 44-45 (in Chinese)

18. Pradhan L, Pattnaik R, Sahoo A. Calophyllum inophyllum-an 
economic tree in coastal tract of Orissa. Environment and Ecology, 1998, 16(2): 476-477

19. Yang X, Fang J. Analysis of the development and application value of Calophyllum inophyllum L. Chinese Wild Plant Resources, 2001, 20(6): 33-35 (in Chinese)

20. Ito C, Itoigawa M, Miyamoto Y, Rao K S, Takayasu J, Okuda Y, Mukainaka T, Tokuda H, Nishino H, Furukawa H. A new biflavonoid from Calophyllum panciflorum with antitumorpromoting activity. Journal of Natural Products, 1999, 62(12): 1668-1671

21. Pawar K D, Joshi S P, Bhide S R, Thengane S R. Pattern of anti-HIV dipyranocoumarin expression in callus cultures of Calophyllum inophyllum Linn. Journal of Biotechnology, 2007, 130(4): 346-353

22. Friday J, Okano D. Calophyllum inophyllum (kamani). Species Profiles for Pacific Island Agroforestry, 2006, 2(1): 1-17

23. Su Y, He L. Study on the components of fat acids in the oil from seeds of Calophyllum inophyllum L. Chinese Journal of Analysis Laboratory, 2007, 26(6): 62-64 (in Chinese)

24. Timmer V R, Armstrong G. Growth and nutrition of containerized Pinus resinosa seedlings at varying moisture regimes. New Forests, 1989, 3(2): 171-180

25. Dumroese R K, Page-Dumroese D S, Salifu K F, Jacobs D F. Exponential fertilization of Pinus monticola seedlings: nutrient uptake efficiency, leaching fractions, and early outplanting performance. Canadian Journal of Forest Research, 2005, 35(12): 29612967

26. Shedley E, Dell B, Grove T. Diagnosis of nitrogen deficiency and toxicity of Eucalyptus globulus seedlings by foliar analysis. Plant and Soil, 1995, 177(2): 183-189

27. Huang Y Z, Feng Z W, Li Z X, Li X D, Yang B Q. Diagnosis of foliar nutrients (N, P, K, Ca, Mg, B) of young Eucalyptus urophylla trees. Acta Ecologica Sinica, 2002, 22(8): 1254-1259 (in Chinese)

28. Li Y, Liu X, Ma J, Shi G, Yang S. Effects of topdressing nitrogen on growth and nutrient status in leaves of Phoebe chekiangensis container seedlings. Journal of Nanjing Forestry University, 2016, 40(1): 33-38

29. Wu F Z, Bao W K, Li F L, Wu N. Effects of drought stress and N supply on the growth, biomass partitioning and water-use efficiency of Sophora davidii seedlings. Environmental and Experimental Botany, 2008, 63(1-3): 248-255 (in Chinese)

30. Wei H X, Xu C Y, Ma L Y, Jiang L N, Jiang C J, Liu F S, Zhang Q C. Nutrient uptake of Larix olgensis seedlings in response to different exponential regimes. Acta Ecologica Sinica, 2010, 30(3): 0685-0690 (in Chinese)

31. Zhang D, Chen Z X, Huang S N. Effects of fertilization on growth of Archidendron clypearia seedlings. Forest Research, 2015, 28(6): 906-909 (in Chinese)

32. Brown K R, Thompson W A, Camm E L, Guy R D, Hawkins B J. Effects of $\mathrm{N}$ addition rates on the productivity of Picea sitchensis, Thuja plicata, and Tsuga heterophylla seedlings. Trees, 1996, 10(3): 189-197

33. Nakaji T, Takenaga S, Kuroha M, Iuta T. Photosynthetic response of Pinus densiflora seedlings to high nitrogen load. Environmental Sciences, 2002, 9(4): 269-282

34. Timmer V R. Exponential nutrient loading: a new fertilization technique to improve seedling performance on competitive sites. New Forests, 1997, 13(1): 279-299

35. Salifu K F, Jacobs D F. Characterizing fertility targets and multielement interactions in nursery culture of Quercus rubra seedlings. Annals of Forest Science, 2006, 63(3): 231-237

36. Cortina J, Vilagrosa A, Trubat R. The role of nutrients for improving seedling quality in drylands. New Forests, 2013, 44(5): 719-732

37. Schott K M, Snively A E K, Landhäusser S M, Pinno B D. Nutrient loaded seedlings reduce the need for field fertilization and vegetation management on boreal forest reclamation sites. New Forests, 2016, 47(3): 1-18 